\title{
Archéopages
}

Archéopages

Archéologie et société

Hors-série 2 | 2010

Archéologie sans frontières

\section{Collaboration franco-américaine sur des corpus céramiques de sites coloniaux}

\section{Steven Pendery}

\section{(2) OpenEdition}

1 Journals

Édition électronique

URL : https://journals.openedition.org/archeopages/774

DOI : 10.4000/archeopages. 774

ISSN : 2269-9872

\section{Éditeur}

INRAP - Institut national de recherches archéologiques préventives

\section{Édition imprimée}

Date de publication : 1 octobre 2010

Pagination : 60-61

ISSN : 1622-8545

\section{Référence électronique}

Steven Pendery, "Collaboration franco-américaine sur des corpus céramiques de sites coloniaux », Archéopages [En ligne], Hors-série 2 | 2010, mis en ligne le 01 octobre 2010, consulté le 23 février 2023. URL : http://journals.openedition.org/archeopages/774 ; DOI : https://doi.org/10.4000/ archeopages. 774 
de faire progresser la recherche sur la céramique, mais aussi, plus largement, sur la culture matérielle des sites d'époque moderne (Pendery, 2007 b) pour étudier la part des traditions et des innovations dans les pratiques culturelles et sociales des populations du Nouveau Monde.

Augeron M., Guillemet D. (DIR.), 2004, Champlain ou les portes du Nouveau-Monde. Cinq siècles d'échanges entre le Centre-Ouest et l'Amérique du Nord XVI ${ }^{e}$-XXI ${ }^{e}$ siècles, La Crèche, Geste Éditions, p. 414.

Chami E., 1963, «L'art céramique du Beauvaisis aux Xve et XVI siècles », Revue de la céramique, du verre et des arts du feu, 3o, p. 95-96.

CôTÉ H., à paraître, « La collection archéologique du site CartierRoberval : témoignage unique d'un projet colonial français en Amérique ", in Pendery S., Ravoire F. (ÉD.), Histoire et Archéologie des $X V I^{e}$ et $X V I I^{e}$ siècles, actes du colloque 2, Congrès national des sociétés historiques et scientifiques, Québec, 2008, CTHS.

Grenier R., Bernier M.-A., Stevens W. (ÉD.), 2007, L'Archéologie subaquatique de Red Bay: La construction navale et la pêche de la baleine basque au XVI ${ }^{e}$ siècle, vol. II, p. 120-130.

Guimont J., 1996, La Petite-Ferme du cap Tourmente. De la ferme de Champlain aux grandes volées d'oies, Septentrion, $230 \mathrm{p}$.

Herzog A., à paraître, « Lîle du Petit Mécatina sur la Basse-Côte-Nord du Québec - résultats préliminaires des analyses céramiques d'un site voué aux activités de pêche saisonnière dans le golfe du Saint-Laurent entre le XVI ${ }^{\mathrm{e}}$ et le XVIII ${ }^{\mathrm{e}}$ siècle », in Pendery S., RavoIre F. (ÉD.), Histoire et Archéologie des $\mathrm{XVI}^{e}$ et $\mathrm{XVII}^{e}$ siècles, actes du colloque 2, Congrès national des sociétés historiques et scientifiques, Québec, 2008, CTHS.

Moussette M., Moss W., 20o8, "Québec au temps de Champlain », in Rêves d'Amériques : Regard sur l'archéologie de la Nouvelle-France, Archéologiques, collection Hors Série 2, Association des Archéologues du Québec, p. 18-37.

Niellon Fr., MoussetTe M., 1985 (rééd. 1995), L'Habitation de Champlain, Les publications de Québec, Collection Patrimoines, Dossier n ${ }^{\circ} 58,531 \mathrm{p}$

Niellon Fr., 2008, "Québec au temps de Champlain », in Rêves d'Amériques : Regard sur l'archéologie de la Nouvelle France, Archéologiques, collection Hors Série 2, Association des Archéologues du Québec, p. 1-17.

Pendery S., 2007 a, « Île Sainte-Croix, Lieu historique international, Calais (Maine) (1604-1605), Histoire, Archéologie, Interprétation », in Medieval Europe in Paris, Colloque INHA, Paris, septembre 2007. Cf. http://medieval-europe-paris-2007.univ-paris1.fr.

Pendery S., 2007 b, « La vie matérielle aux centres urbains des colonies anglaises », in Medieval Europe in Paris, Colloque INHA, Paris, septembre 2007. http://medieval-europe-paris-2007.univ-paris1.fr.

Pendery S., à paraitre, Ravoire F. (ÉD.), Histoire et Archéologie des $X V I^{e}$ et $X V I I^{e}$ siècles, actes du colloque 2, Congrès national des sociétés historiques et scientifiques, Québec, 2008, CTHS.

Pieters M., 1993, « Laat-middeleeuwse landelijke bewoning achter de Gravejansdijk te Raversijde (stad Oostende, prov. WestVlaanderen) ", in Archeologie in Vlaanderen, III, p. 281-298.

POPE P., 2007, « Le temps des pêches lointaines : vestiges des rythmes vernaculaires transatlantiques », http://medieval-europeparis-2007.univ-paris1.fr/P.Pope.pdf.

Pope P., Batt M., 2008, « Post-medieval Breton earthenwares in Newfourndland ", Post-medieval Archaeology, 42/1, p. 48-74.

RAvoire F., 1997, La Céramique de terre cuite en Île-de-France entre la fin $d u X V^{e}$ et la première moitié $d u X V I I^{e}$ siècle : définition d'un faciès régional, Thèse de doctorat nouveau régime de l'Université Paris I-Panthéon Sorbonne, 4 vol., 974 p.

Ravoire F., 2008, «Pour une archéologie du quotidien : objets et céramiques modernes ", in Constructions de l'archéologie, Archéopages, Hors-Série, Inrap, p. 33-35

RAVOIRE F., 2009, «Du vaisselier médiéval au vaisselier moderne: modalités et formes d'une évolution en Île-de-France ( $\mathrm{XIV}^{\mathrm{e}}-\mathrm{XVI}^{\mathrm{e}} \mathrm{s}$.) », dans Ravoire F., Dietrich A. (DIR.), La Cuisine et la table en France à la fin du Moyen Âge: contenus et contenants du XIV $V^{e}$ au $X V I^{e}$ siècle, Actes du colloque de Sens (8-10 janvier 2004), Caen, édition du Crahm, p. 249-270.

RAVOIRE F., à paraître, « Les céramiques en usage à Paris et dans les grandes villes côtières françaises au XVI ${ }^{\mathrm{e}} \mathrm{s}$. et au début du XVII $\mathrm{e}$. : contribution l'identification des productions exportées sur les sites coloniaux nordaméricains », Pendery S., Ravoire F. (ÉD.), Histoire et Archéologie des $X V I^{e}$ et $X V I I^{e}$ siècles, actes du colloque 2 , Congrès national des sociétés historiques et scientifiques, Québec, 2008, CTHS

RAVOIRE F., à paraître, " Les céramiques de France septentrionale », in Belan G., Journot F., Archéologie moderne et contemporaine en France, Paris, Éditions La Découverte.
L'aide déterminante de l'Inrap

pour la compréhension du site Cartier-Roberval (Québec)

Hélène Côté

Commission de la capitale nationale du Québec (CCNQ)

En 2005, la découverte du plus ancien établissement européen au nord du Mexique, le fort érigé par Jacques Cartier et Jean-François de la Rocque de Roberval en 1541, a posé plusieurs défis aux archéologues de la CCNQ. En effet, ce site archéologique recèle une culture matérielle très peu connue des chercheurs spécialisés sur la période dite «euro-américaine», car aucune collection d'artéfacts d'origine française datant de la première moitié du XVI ${ }^{\mathrm{e}}$ n'avait été mise au jour en Amérique jusqu'à ce jour.

En 2008, le congrès du CTHS, tenu à Québec, a été l'occasion d'entamer une collaboration avec Fabienne Ravoire, céramologue à l'Inrap. Lors de cet événement, l'équipe d'archéologues de la CCNQ a reçu Fabienne Ravoire au laboratoire et réserve d'archéologie du Québec pour l'identification et la provenance des céramiques provenant de cette fouille. Cette céramologue a aussi été d'une aide précieuse pour établir des liens entre l'équipe de la CCNQ et des archéologues français, notamment en organisant la visite de plusieurs laboratoires de Normandie, de Bretagne, de l'Ouest (Loire-Atlantique) et du Sud-Ouest. Ces visites et rencontres ont été d'une aide inestimable pour l'équipe d'archéologues québécois afin d'augmenter leurs connaissances sur la céramique du XVI ${ }^{\mathrm{e}}$ siècle et créer un réseau de chercheurs dont les connexions produisent des retombées scientifiques insoupçonnées, par exemple pour l'identification des creusets de Louviers sur le site Cartier-Roberval.

\section{Collaboration franco-américaine sur des corpus céramiques de sites coloniaux}

Steven Pendery

Senior Archeologist, Northeast Region, National Park Service, USA

Ma collaboration avec Fabienne Ravoire fait suite à mes interrogations sur les origines de céramiques post-médiévales d'un site français en Amérique du Nord, occupé pendant une courte période du XVII ${ }^{\mathrm{e}}$ siècle : 1604-1613. Je me doutais que les informations recueillies intéresseraient les spécialistes français de la céramique et les archéologues, c'est pourquoi j'ai été mis en contact avec cette spécialiste de l'Inrap, grâce à Laurier Turgeon, de l'Université Laval (Québec).

Ayant travaillé précédemment sur des sites médiévaux et modernes français, je savais que relativement peu de céramologues modernistes étaient susceptibles de connaître les corpus de produits issus de diverses régions de fabrication. Or, ce fut sans aucun doute le cas du grès, d'où 
la recherche d'un collaborateur connaissant la céramique d'un grand centre urbain où se concentrerait une grande variété de céramiques régionales. Fabienne Ravoire s'est avérée idéale pour ce rôle, d'abord en raison de sa recherche exhaustive sur les céramiques de la cour du Louvre. Ensuite, son travail au sein de l'Inrap lui avait donné l'occasion d'expertiser d'autres ensembles provenant de fouilles diverses. En outre, les sites archéologiques, couvrant un grand éventail chronologique, sur lesquels travaillent les archéologues et les spécialistes de l'Inrap leur apportent une meilleure compréhension de la culture matérielle de la période moderne. Cette connaissance se révèle essentielle pour l'étude de l'expansion mondiale de l'influence française aux XVI ${ }^{\mathrm{e}}, \mathrm{XVII}^{\mathrm{e}}$ et XVIII ${ }^{\mathrm{e}}$ siècles.

Les résultats attendus de cette collaboration sont multiples : comprendre plus précisément les types d'objets régionaux français trouvés en Amérique du Nord, toutes époques confondues; améliorer la datation et la compréhension de la culture matérielle française en France grâce à une précision de datation sur les sites coloniaux, dont l'occupation est souvent brève ; appréhender l'expérience coloniale française et l'impact du Nouveau Monde sur les cultures traditionnelles françaises. Ces objectifs ambitieux s'appuient sur une collaboration à plusieurs niveaux, de l'étude d'objets individuels à l'organisation de conférences internationales intégrant les archéologues et spécialistes de l'Inrap, comme en juin 2008 celle du CTHS qui s'est tenu à Québec. Depuis, notre collaboration se poursuit et nous nous sommes assurés qu'elle sera longue et fructueuse. 